NEWS

\title{
UK physics council sees grim future
}

\section{Second financial crisis in two years leaves researchers questioning the council's long-term viability.}

Britain's high-energy physicists and astronomers are bracing themselves for budget cuts.

The Science and Technology Facilities Council (STFC), which funds the United Kingdom's astronomy, particle- and nuclear-physics communities, is short by roughly $\mathfrak{E} 40$ million (US\$66 million) in its annual $£ 450$-million cash budget. High-energy-physics grants have already been affected, and in a bid to contain costs the council said last week that it would probably withdraw from the multinational Gemini telescope project in 2012.

It is the second such budgetary dilemma for the STFC. The council was formed from the merger of two other councils in April 2007, at the same time as the UK government was undergoing a triennial budget review. "It was a perfect storm" of financial pressures, says Paul Crowther, an astrophysicist at the University of Sheffield. Within months, the newborn STFC announced that it was facing an $£ 80$-million budget gap.

The latest problems have made physicists angry once more. "This second crisis makes clear that the STFC is incapable of being run in its current form," argues Brian Foster, a particle physicist at the University of Oxford.

Things are likely to worsen in the coming months. Throughout the autumn, physicists have met to prioritize projects in areas supported by the council. The prioritization will be used to determine how to spend money within the current budget levels, says Terry O'Connor, the STFC's director of communications.

High-energy physicists have already seen their latest grants funded for one year rather than for the standard three to five. That makes it difficult to support postdocs and hire technical staff, says Phil Allport, a particle physicist at the University of Liverpool. And the change comes as scientists are gearing up to study data from the Large Hadron Collider (LHC) near Geneva, Switzerland. "Just as collisions are starting in the LHC, the United Kingdom may not be able to adequately exploit it," Allport says.

Astronomers are also feeling the pinch. The proposed withdrawal from the Gemini Observatory, a pair of eight-metre telescopes in Hawaii and Chile, echoes a 2007 council announcement that it later cancelled. This time, a review panel of academics made the decision, says Andrew Fabian, an astronomer at the University of Cambridge and president of the Royal Astronomical Society. "We feel that

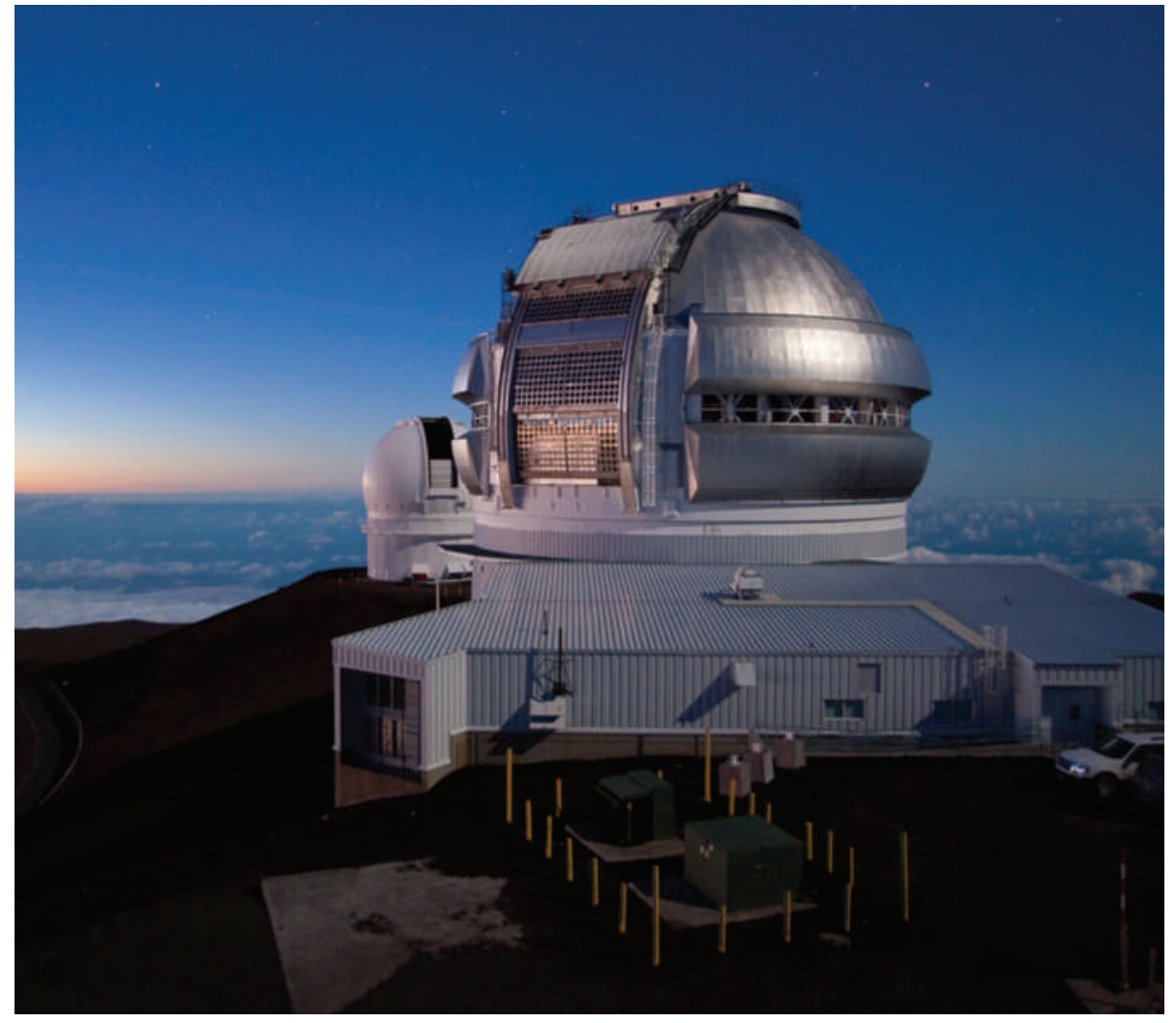

UK astronomers may lose access to the Gemini North Observatory in Hawaii through cost cutting.

the current package we have with Gemini does not give us a big enough benefit," he says.

Nuclear physicists' dreams for the future are also being affected by the cash problems. UK researchers had hoped that Britain would become a partner in the multinational Facility for Antiproton and Ion Research, now being planned at the GSI Helmholtz Centre for Heavy Ion Research in Darmstadt, Germany. But the budgetary shortfall has left those plans in question, says Bill Gelletly, a nuclear physicist at the University of Surrey in Guildford.

The origins of the shortfall are complex. In 2007, the STFC proposed deep cuts to deal with its financial problems. The UK government responded by allowing the council to borrow money from future years and by providing some support to compensate for currency fluctuations. "The outcry got the attention of people high up," says Crowther, but "it didn't make the problem go away."

Since then, the weakened pound has made it increasingly difficult for the STFC to pay its overseas subscription fees to international facilities such as CERN, the lab that houses the LHC. In addition, repayment of the money borrowed from future years is now due. A 2008 prioritization cut grant renewing by a quarter, but that was not enough to make up the shortfall.

Many who depend on the council for funding can barely contain their anger. "We've had scientific prioritization after scientific prioritization," says George Efstathiou, director of the Kavli Institute for Cosmology at the University of Cambridge. "Why has this organization still not got its programme sorted out?"

O'Connor says the council is doing the best it can at a time when the country's economic future stands at a crossroads. The uncertainty "is not confined to particle physics, nuclear and astronomy", he says, "it's right across the research base - it's right across the economy".

The council is now looking beyond its current three-year spending plan to establish a five-year programme and a ten-year strategy, he says.

Geoff Brumfiel 